Pteridines

Vol. 11, 2000, pp. $100-105$

\title{
Photoinduced cleavage of pasmid DNA in the presence of pterin
}

\author{
Carolina Lorente ${ }^{(a)}$, Andrés Héctor Thomas ${ }^{(a)}$, Laura Sofia Villata ${ }^{(a)}$, Daniela Hozbor ${ }^{(b)}$, Antonio Lagares ${ }^{(b)}$ and \\ Alberto Luis Capparelli ${ }^{(2)}$
}

(a) Instituto de Investigaciones Fisico químicas Teóricas y Aplicadas (INIFTA), Departamento de Química, Facultad de Ciencias Exactas, Universic'ad Nacional de La Plata, Casilla de Correo 16, Sucursal 4, (1900), La Plata, Argentina. E-mail: alcappa@da!ton.quimica.unlp.edu.ar ; (b) Instituto de Bioquímica y Biología Molecular (IBBM), Departamento de Cit ncias Biológicas, Facultad de Ciencias Exactas, Universidad Nacional de La Plata. 47 y 115 (1900) La Plata, Ar६̨entina. E-mail: lagares@nahuel.biol.unlp.edu.ar

\section{Sumnary}

The photoinduced cleavage of plasmid 1)NA by UV-A light in the presence of pterin was investigated. Electrophoretic analysis of the irradiated plasmid pUC18 in the presence of pterin showed that UV light of 350 $\mathrm{nm}$ induced the transformation of a significint proportion of the supercoiled plasmid to its relaxed form. A minor proportion of plasmid forms are also con'erted to the linear plasmid isomer at the longer irradiation times. All these transformations during irradiation can be observed in the absorption spectrum of DNA as function of time. Such spectral modifications correlated with the extent and the kinetics of plasmid relaxation, but not with the appearance of the linear plasmid. None of the:e changes were operative without the irradiation with UV-A light. Control experiments with pterin or plasmid D VA irradiated separately, showed no photochemical changes. Results taken together suggest that the observed changes in the supercoiled plasmid as well as the spectral modifications both derive from the generation of singls-strand break in the DNA.

\section{Introduction}

As reported in the literature, pterins have been suspected as photoinducer of genetic alterations. The importance of this effect is mainly associated with the broad band absorption at wavelength larger than 320 nni. This fact makes relevant the effect of solar irradiation in the UV-A region on those biological systems where pterins could be accumulated. This suggestion was advanced in the last eighties (1).

Several studies are reported in the literature describing the interaction of DNA with UV radiation. Dimers of pyrimidine are normal photoproducts resulting from this interaction (2). Such changes were observed in vitro and also in living organisms when DNA is exposed to UV-B (290-320 nm) radiation. Chemical changes in DNA induced by UV light result in mutagenic and carcinogenic alterations. These changes induce molecular processes competing with those involved in enzymatic reaction for repairing the DNA damage. If the later process is low enough, a genetic failure will be transmitted to the new cell (3). It has been shown that UV-B radiation is able to induce several types of skin cancer (4).
Experiments with cells showed that UV-A light $(320-380 \mathrm{~nm})$ is also mutagenic and carcinogenic $(5,6)$. However, DNA does not present detectable absorption in this wavelength range. These results are of biological significance because UV-A is mainly present in the solar radiation reaching the earth surface. Indirect processes may produce genetic damage induced by UV-A radiation. In fact, photoactivation of a second molecule may start a series of processes when interacting with DNA, even its denaturation and/or fragmentation (7).

Previous reports support these photoactivated processes involving the participation of other molecules that are photoactive in this wavelength region leading to the DNA and RNA photocleavage. These molecules can be referred as "photocleavers" or "photocleavage agents" (7), which can be organic compounds, such as anthraquinones $(8,9)$, dibenzoyldiazomethane (10), 2-aminoimidazolone (11), 6-(2-pyridinium)phenanthridinium (12), porphyrins (13) or metal complexes (7), particularly those of ruthenium, vanadium, copper, cobalt. Several of these complexes have been proposed as model probes in photocleavage studies.

Correspondence to: Alberto Luis Capparelli,

Casilla de Correo 16, Sucursal 4, (1900), La Plata, Argentina. 
As shown is Some biomadis. $:-$ dies suggest that pterins are involved :- :- :

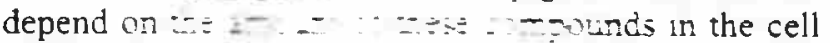
(14). Moreover, a zieni siudy snowed that pterin, 6carboxypterin and folic acid are able to induce the hydroxylation of deoxyguanosine in calf thymus DNA (15). In the light of these facts, it is interesting to look after the potential effects of these compounds as putative photoinducer of skin cancers in living organisms.

In this paper we report in vitro experiments performed on supercolled PUC18 plasmid DNA and analyze the extension of alteration and even damage photoinduced by pterin.

Fig.1: Absorption spectrum of aqueous solution of pterin $6.8 \times 10^{-5} \mathrm{M}$ at $\mathrm{pH} 6.5$ and $25^{\circ} \mathrm{C}$.

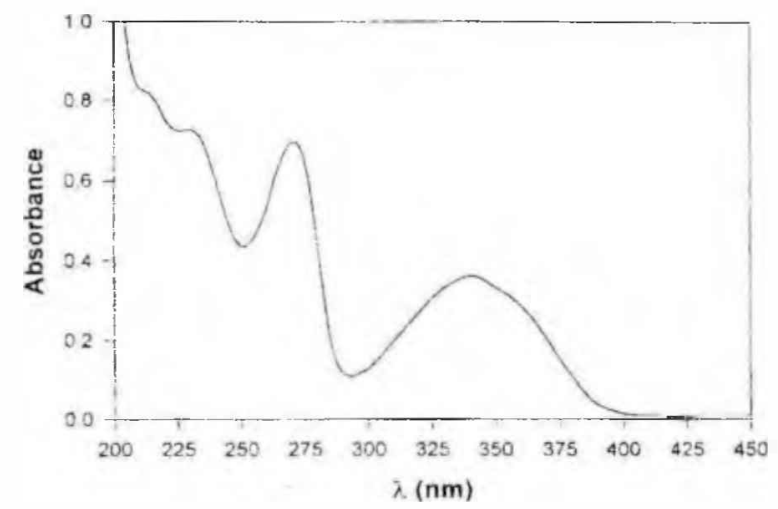

Materials and methods

\section{Materials}

pUC18 plasmid DNA was isolated in our laboratory from Escherichia coli DH5a (pUC18) using the alkaline lysis procedure according to (16) and further treated with RNAase (from Sigma) and phenol (from Carlo Erba)-tris in order to eliminate contaminating RNA and proteins. A final step of isopropanol precipitation was carried out to concentrate DNA in sterile aqueous solutions. The absorbance ratio $\mathrm{A}^{260} / \mathrm{A}^{280}$ was used as a purity control of the sample. In all our samples, this ratio was $\approx 2$, being that indicative of a low or almost negligible protein content in the starting DNA.

EcoRI (from Promega) was used for linearizing the plasmid forms. The experiniental conditions employed are reported elsewhere

Pterin p.a. (Sigma). L-histidine (from Fluka) and methanol (from Merck) were ised without further purification.

Experiments were performed in solutons free of oxygen (in atmosphere of $\mathrm{N}$. free o: $\mathrm{O}, \mathrm{O}=\mathrm{Hel}$. in presence of air and saturated with o. uliapure. respectively.

\section{Photochemical studies}

Experiments were performed under continuous irradiation in quartz cells of $0.6 \mathrm{ml}$ and $0.2 \mathrm{~cm}$ optical path. Rayonet lamps RPR (3500 $\AA$ ) provided by Southern N.E. Ultraviolet Co. were employed. The $\mathrm{pH}$ of DNA and pterin solution: was adjusted to 6.5 before irradiation. The whole experiments were carried out at $25^{\circ} \mathrm{C}$. Further experimental details are given in figure legends.

Absorption spectra of solutions were taken after a few seconds till 2 hours of photolysis. Spectral changes of irradiated DNA and pterin were analyzed in the range $200-450 \mathrm{~nm}$. U $\checkmark$-Visible spectra were performed on a Cary 3 (Varlan) spectrophotometer, using a program for smoothing and averaging signals.

Control experiments showeil that the spectrum of DNA plus pterin before irradia ion resulted exactly the additive combination of the individual spectra of pterin and DNA (not showr). No changes in the absorption spectrum of DNA were observed, even after 120 minutes of continuous irradiation. Moreover. no significant changes in the absorption spectra of pterin solutions were observed during 120 minutes of irradiation.

\section{Electrophoretic runs}

Electrophoretic runs of control and irradiated plasmid samples were perforned in $0.8 \%$ agarose gels using TBE buffer $(0.045$ M Trisborato/0.001EDTA). DNA was visualized with ethidium bromide (Sigma, $1 \mathrm{mg} / \mathrm{ml}$ ) under UV illumination.

Three major forms of plasmid DNA can be detected. The form with a higher mobility corresponds to a supercoiled structure whereas the second one should be a more relaxed form. The third band corresponds to dimeric species of plasmid DNA. Intensities on the gel are proportional to the amount of DNA. When DNA containing solutions are treated with the restriction enzyme EcoRI, all the forms present are transformed to a plasmid form presenting only one electrophoretic band. This band corresponds to a linear form as expected.

FOTODYNE recorder with a UV transiluminator and a POLAROID camera were employed. The film negatives were scanned in a Hewlett Packard scanner. The intensity spots were integrated using the Sigmagel (Jandel $\mathrm{Co}$ ) program. In order to compare different lanes of the same gel, a normalization procedure was adopted: the intensity of each spot was divided by the sum of the intensities of all spot in each lane. The lesser intercalation of ethidium into supercoiled DNA was taken into account by dividing the corresponding intensity by $0.8(17)$. 


\section{Results}

Electrophoretic analysis of plasmid pUC18 irradiated with $U V-A$ light in the presence of pterin.

To investigate the characteristics of the photoinduced cleavage of DNA by pterin, samples of plasmid pUC18 were analyzed by agarose gel electrophoresis after different irradiation times using UV-A light at $350 \mathrm{~nm}$. As shown in Figure 2, the DNA solutions irradiated in the presence of pterin showed an increase in the relaxed plasmid form concentration and a simultaneous reduction in the supercoiled form concentration. In addition to these observations, a new plasmid form was detected at longer than 60 minutes irradiation times. This new form presents an electrophoretic mobility coincident with that of pUC18 linearized form obtained after digestion with restriction enzyme EcoRI. No electrophoretic changes were observed in plasmid DNA solutions containing pterin and kept in the dark several hours. Control experiments using plasmid solutions without pterin did not show any electrophoretic change after irradiation.

Fig.2: Electrophoretic runs. Lane 1: solution of pterin $\left(1 \times 10^{5} \mathrm{M}\right)$ and plasmidic DNA $\left(3.8 \times 10^{-5} \mathrm{M}\right.$ in bp) irradiated during 140 minutes. Lane 2: control of non irradiated DNA solution of equal concentration. Lane 3: solution of lane 1 before irradiation. Lane 4: pattern of the enzymatically linearized plasmid.

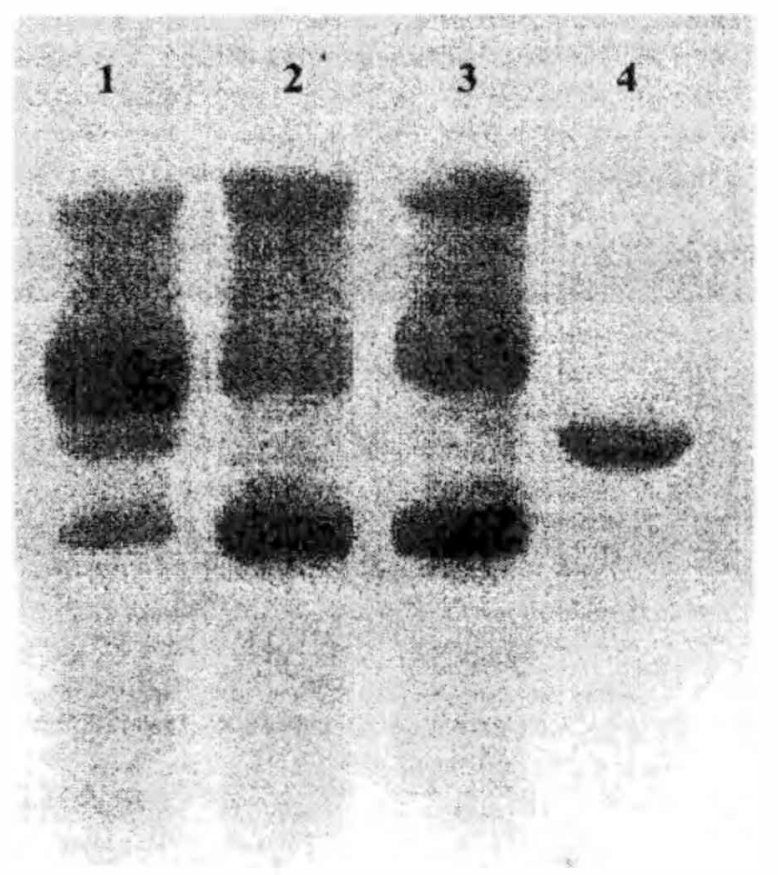

Figure 3 shows the time evolution of relative concentrations of relaxed and supercoiled plasmid forms in irradiated solution of plasmid pUC18 in the presence of pterin. The increase in the relaxed form concentration correlated well with the decrease in the supercoiled form concentration

Fig.3.: Time evolution of relative soncentrations of plasmid forms in irradiated solunon of plasmid pUC18 (3.8 $\times 10^{-} \mathrm{M}$ in bp) in the presence of pterin $\left(1 \times 10^{-5} \mathrm{M}\right)$ Intensities of supercolled plasmids were corrected as reported in the literature $\left(1^{-}\right.$,

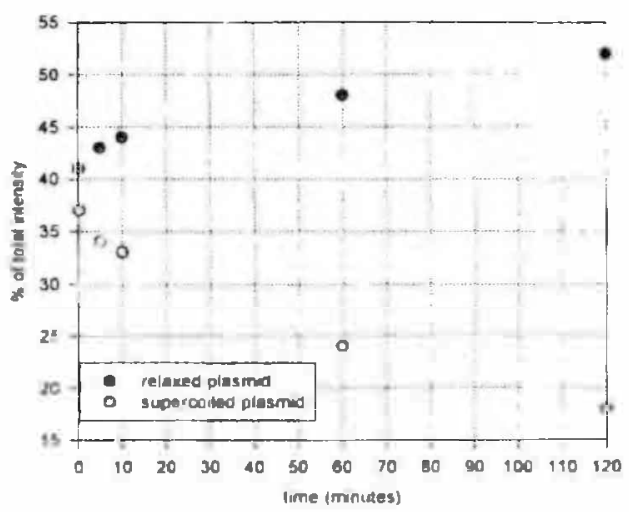

\section{Spectral changes}

"o investigate the spectral characters of plasmid pIC 18 before and after irradiation with UV-A light in the presence of pterin, the spectra were recorded at d.fferent irradiation-times (0-120 minutes) and plotted is shown in Figure 4. DNA spectra changed in time, with an increase in the absorbance in the range of 220 to $300 \mathrm{~nm}$.

Fig.4: (a) Evolution of the absorption spectra of solutions of plasmid DNA $\left(3.8 \times 10^{5} \mathrm{M}\right.$ in bp) irradiated in the presence of pterin $\left(1 \times 10^{-5} \mathrm{M}\right)$, as a function of irradiation time. In this Figure, the spectrum of a $\left(1 \times 10^{5} \mathrm{M}\right)$ pterin solution was subtracted to the experimental spectra recorded at the different times. (b) Difference spectra obtained after subtracting to the spectra at different times the corresponding one at $t=0$.

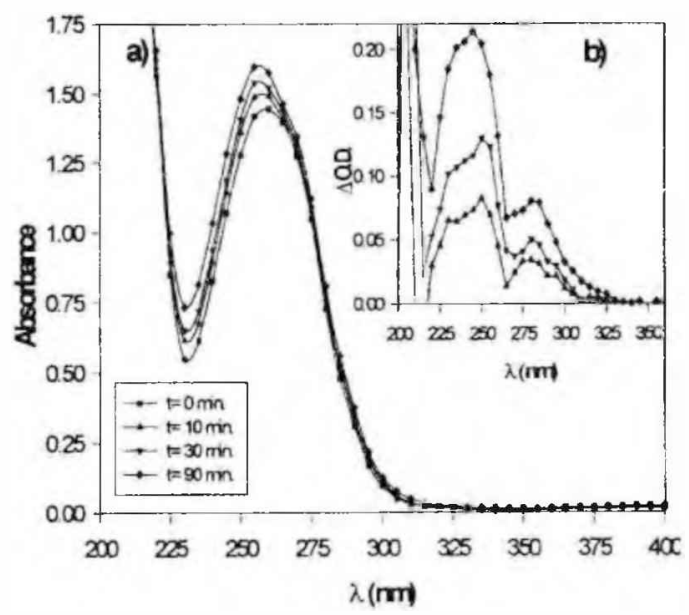

Unauthenticated Download Date | 8/23/19 8:29 PM 
In another set of experiments, shown in Figure 5, the variation of absorbance at $260 \mathrm{~nm}$ along the first two hours of irradiation using different pterin concentrations was analyzed.

Fig.5: Absorbance changes at $260 \mathrm{~nm}$ of plasmid DNA solution ( $5 \times 10-5 \mathrm{M}$ in bp) after irradiation at different pterin concentrations. Solid lines are obtained from fitting a first order law (eq. 1) using the parameters listed in Table 1.

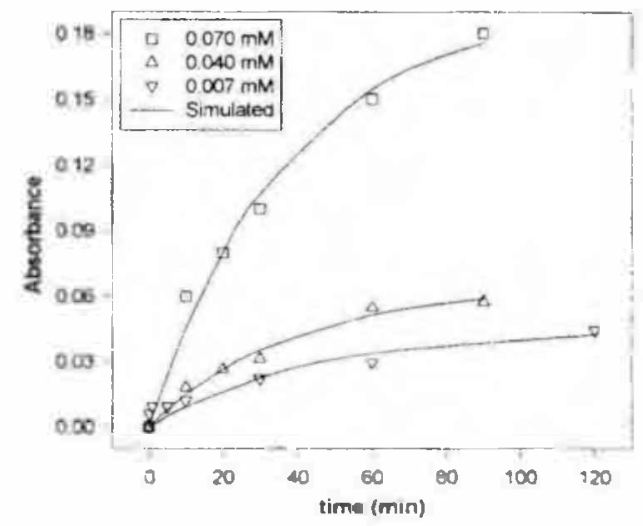

A first order rate law was found to describe the changes in absorbance $\left(A_{t}-A_{0}\right)$ according to the following equation:

$$
\left(A_{t}-A_{0}\right)=\left(A_{x}-A_{0}\right) \cdot[1-\exp (-k \cdot t)] \text {. }
$$

Kinetic constants are presented in table 1 . The first order rate constant was found independent on the pterin concentration as expected. Solid lines in Figure 5 were calculated with this set of parameters.

Tab. 1: Apparent first order rate constants at different pterin concentrations.

\begin{tabular}{c|c|c}
{$[\mathbf{P t}] / \mathbf{m M}$} & $\left(\mathbf{A}_{\alpha}-\mathbf{A}_{0}\right)$ & $\mathbf{k} / \mathbf{m i n}$ \\
\hline 0.007 & 0.04 & 0.0225 \\
0.040 & 0.06 & 0.0259 \\
0.070 & 0.18 & 0.0269
\end{tabular}

Interestingly, the extent of the spectral changes presented a linear correlation with the increase of the relaxed plasmid form (Figure 6 ).

Fig.6: Correlation between the absorbance changes and the relative amount of the relaxed form. Both, absorbance changes and electrophoretic runs match in time. The relative amount of relaxed form is expressed as $I_{r} / I_{0}$, where $I_{0}$ means the "total amount" of DNA estimated by adding the intensities of the different spots in each lane and $I_{r}$ corresponds to the intensity

measured for the relaxed form in the same lane.

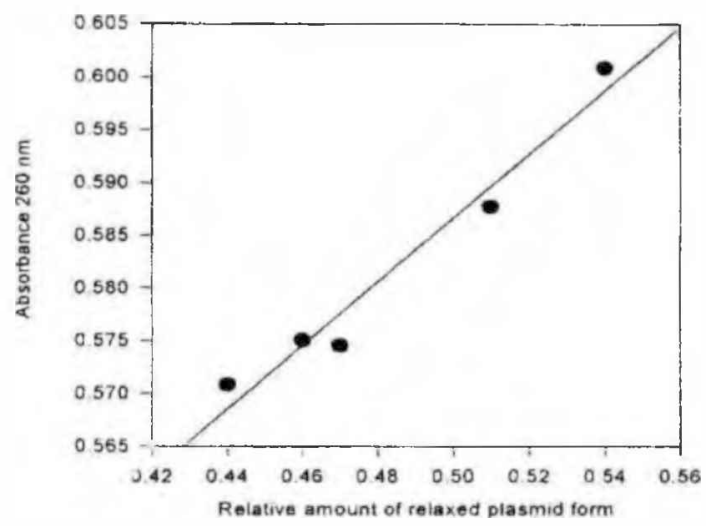

No spectal changes were observed in a solution, made by mixing pterin and DNA, kept in the dark during a few hours. When pterin or DNA solutions were sepcrately irradiated, their absorption spectra do not aiter. In the same way, the absorption band of pterin in the range $300-450 \mathrm{~nm}$ (Figure 1) does not present alterations after the irradiation even in the presence of DNA at this $\mathrm{pH}$.

Analysis of plasmid photolysis in the absence of oxygen and in the presence of selective scavengers.

Experiments carried out in the absence of dissolved oxygen showed comparable results to those performed in either air equilibrated or oxygen saturated. All experimental conditions led to a similar increase in the amount of relaxed DNA plasmid. (Figure 7). The result strongly suggests that molecular oxygen would not be involved in the photolytic cleavage of DNA by pterin, here characterized.

Fig.7: Effect of the oxygen concentration on the photoinduced cleavage of plasmidic DNA $\left(3.8 \times 10^{5} \mathrm{M}\right.$ in $b p)$ in the presence of pterin $\left(1 \times 10^{5} \mathrm{M}\right)$ Lane 1 : non irradiated solution. Lanes 2: irradiated solution in absence of $\mathrm{O}_{2}$. Lanes 3: saturated in $\mathrm{O}_{2}$ irradiated solution. Lanes 4 aerated irradiated solution. The irradiation time was 120 minutes.

1

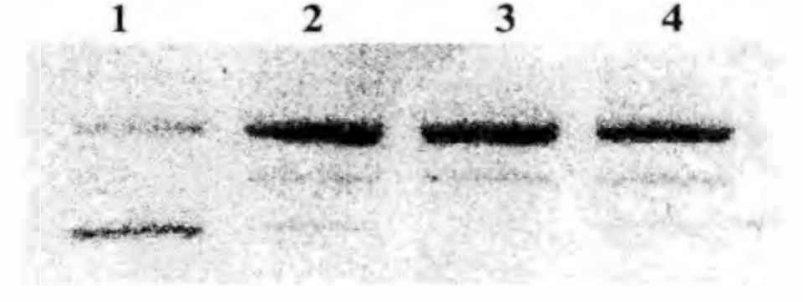

In addition plasmid cleavage was not inhibited in the presence of $1.2 \mathrm{mM}$ histidine, a singlet oxygen scavenger. Similarly, DNA cleavage was observed in $1.7 \mathrm{mM}$ methanol, an active quencher agent of hydroxyl radical (18). 


\section{Discussion}

Here we analyzed the photolysis of a plasmid substrate to characterize the kinetics of the proccess. According to evidence from our laboratory pterin-6carboxylic acid and folic acid but not pterin are photolyzed under UV-A illumination. While radical intermediates are detected in the first stage of the photolysis of folic acid (19), pterin-6-carboxilic acid photolyses with the release of $\mathrm{CO}_{2}(20)$. Thus, it is not straight forward the assignment of an active role in DNA damage to pterin-6-carboxilic acid derivatives themselves. To circumvent this problem we used pterin as photocleaver agent.

Results show that irradiation of DNA in the presence of pterin leads in the short time (minutes) to a continuous increase of the DNA absorbance at 260 $n m\left(A^{360}\right)$. Changes in the $A^{260}$ follow first order kinetics and a parallel increase in the circular relaxed plasmid form takes place. These observations strongly support the possibility that spectral changes resulted from the conversion of the supercoiled plasmid to its relaxed form after a single strand break within the DNA helix. This interpretation is in agreement with the observed linear dependence between the $A^{260}$ and the amount of the relaxed plasmid form, each of them sampled at identical irradiation times (Figure 6). The appearance of the linear plasmid form at long irradiation times might be due to a structural requirement of at least two close breaks in the opposite DNA strands.

Results suggest that early changes in the spectral absorption of the DNA after irradiation as well as those changes observed later in the electrophoretic pattern are consequence of cumulative breaks in both DNA strands (Figure 8).

Fig.8: Time sequence of spectral and electrophoretic changes during pUC18 irradiation. S: supercoiled plasmid; Ri: relaxed plasmid; $\mathrm{Li}$ : linear plasmid; 1 : breaks number.

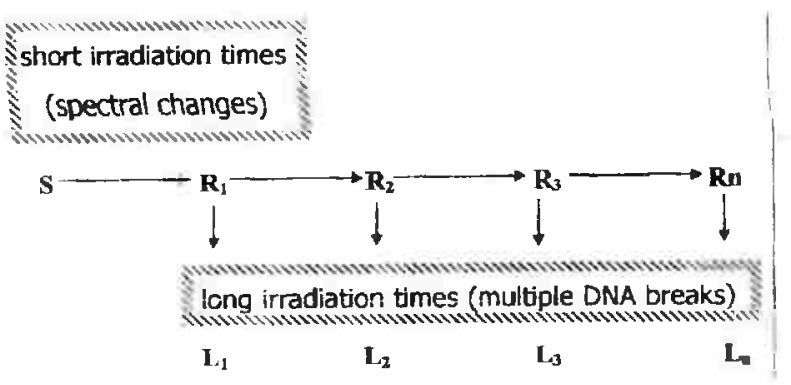

Assuming a random model for the location of the UV-A photoinduced breaks within the plasmid sequence, the probability that a given break (n) could result in a linear form should increase with $n$. Although accumulation of many breaks along the linear plasmids could result in plasmid fragmentation at long irradiation times. We have no experimental evidence of such phenomenon.

Regarding the type of mechanism by which pterin participates in the photocleavage of DNA, no evidence was yet obtained to support a direct interaction pterin-nucleic acid. Photoexcited pterins lost energy through radiative and non-radiative pathways. The observation that pterin absorption does not charge in intensity or shape after the mixture with DNA, jarticularly in the region of $1>320 \mathrm{~nm}$, suggests that p.erins do not directly bind to DNA or that their bindi $\mathrm{g}$ affinity is too low to be detected under our exper imental conditions.

Thise are several mechanisms of interaction betw sen DNA and photocieavers. At least, three diffe ent groups of processes have been recognized: (1) the photocleavager can abstract hydrogen atoms from the deoxyribose groups of DNA without the requirtment of binding between the nucleic acid and the pnotocleaver, (2) generate a diffusible intermed ate (singlet oxygen or hydroxy radicals) that reacts wits: the nucleic acid to initiate a nonselective strand cleavage of the DNA or (3) operate by single electron-transter through a process that requires the intercalation of the photocleaver. In the reaction described in this work, the observed photocleavage in the absence of disolved oxygen rules out the participation of singlet $\mathrm{O}_{2}$ to induce the DNA damage (Figure 2b). This observation is further supported by similar results obtained in the in presence of Lhystidine, an agent that captures singlet $\mathrm{O}_{2}$ species. Using independent evidence it has been previously suggested that singlet $\mathrm{O}_{2}$ plays little role, if any, in calf thymus photoinduced DNA damage by pterins (15). The DNA damage obtained in the presence of methanol during the irradiation also suggests that $\mathrm{OH}$ radicals would not participate in the photolysis.

\section{Acknowledgements}

This work was supported by the Consejo Nacional de Investigaciones Cientícas y Técnicas de la República Argentina (CONICET, Grant \# 4354), Agencia Nacional de Promoción de Ciencia y Tecnologia (ANPCyT Grant \# PICT 06-03531), the Comisión de Investigaciones de la Provincia de Buenos Aires (CICPBA) and Universidad Nacional de La Plata. C.L. and A.T., respectevely, thank the Comisión de Investigaciones Cientificas $(\mathrm{ClC})$ and CONICET for the student fellowships.

\section{References}

1. Boyle P, Camier R., Chemistry and Biology of Pteridines and Folates, Edit. J. E. Ayling et al., Plenum Press, New Nork, (1993)

2. Stanier R Y., Adelberg E A,. Ingraham J L, Microbiología, $4^{\text {ta }}$ Edición., Reverté, Barcelona, 1984.

3. Drake J W, The molecular basis of mutation, 
Holden- Day, San Francisco, 1970.

4. International Agency for Research on Cancer, Monographs on the evaluation of carcinogenic risks to humans, Solar and UV Radiatıon, vol. 55, International Agency for Research on Cancer, Lyion, Francia, 1992.

5. Tyrrell RM, Keyse SM. The interaction of UV-A radiation with cultured cells. J Photochem Photobiol B: Biol 1990; 4: 349-361.

6. Coohil TP, Peak MJ, Peak JG, The effects of the ultraviolet wavelengths of radiation present in sunlight on human cells in vitro, 1987; 46: 10431050.

7. Armitagge B. Photocleavage of Nucleic Acids. Chem Rev 1998; 98: 1171-1200.

8. Breslin DT, Shuster GB. Anthraquinone photonucleases: Mechanisms for GG-selective and non selective cleavage of double-stranded DNA. J Am Chem Soc 1996; 118: 2311-2319.

9. Ly D, Kan Y, Armitage B, Shuster GB. Cleavage of DNA by irradiation of sustituted anthraquinones: intercalation promotes electron transfer and efficient reaction at GG steps. J. Am Chem Soc 1996; $118: 8747-8748$.

10. Nakatani K, Shiral J, Sando A, Saito I. Guanine specific DNA cleavage by photorradiation of dibenzoyldiazomethane-oligonucleoude

conjugates. J Am Chem Soc 1997: 119: 76267635.

11. Saito I, Kino K. Product analysis of GG-specific photooxidation of DNA via electron transfer: 2aminoimidazolone as a major guanıne oxidation product. J Am Chem Soc 1998; 120: $7373-7374$

12. Colmarejo G, Barcena $M$, Gutierrez-Alonso $M C$. Montero F, Orellana G. DNA photocleavage by novel intercalating 6-(2-pyridinium)phenanthridium viologens. FEBS Letters 1995; 374: 426428.
13. Croke DT, Perrault L, Sari MA et al. Structureactivity relationships fot DNA photocleavage by cationic porphyrins. J Photochem Photobiol B: Biol 1993; 18: 41-50.

14. Schallreuter KU, Wood JM, Pettelkow MR et al. Phosphatidylinositol 4-kinase: gene structure and requirement for yeast cell viability. Science 1994; 263: 1444-1448.

15. Ito $\mathrm{K}$, Kawanishi S. Photoinduced hydroxylation of deoxyguanosine in DNA by Pterins: Sequence specificity and mechanism. Biochem 1997; 36 : 1774-1781.

16. Maniatis SF, Molecular Cloning -a laboratory manual-, 1989, 2d Edition.

1. Bauer W, Vinograd J. The interaction of Closed Circular DNA with Intercalative Dyes. J Mol Biol $19 t 8 ; 33: 141-171$.

18. Wins-Wah Yan V, Kam-Wing Lo K, Kung-Kai Cheung P. Yuen-Chong Kong. Dcoxyribonucleic acid binding and photocleavage studies of Kheniun (I) dipyridophenazine complexes. J Chem Soc. Dalton Trans 1997; 2067-2072.

19. Thomas AH, Garcia Einschlag FS, Feliz MR. Capparelli AL. First steps in the photochemistry of folate in alkaline medium. J Photochem Photobiol A: Chem 1998: 116:187-190.

20. Suare? G, Cabrerizo FM, Lorente C, Thomas $A H$, Capparell AL. Siudy of the photolysis of 6carboxypterin in acid and alkaline aqueous solutions. J Photochem Photobiol A: Chem 2000; $136: 53-57$. 